\title{
Fibrodysplasia ossificans progressiva: Basic understanding and experimental models
}

\author{
Zijuan Qi ${ }^{1,2}$, Jing Luan², Xiaoyan Zhou', Yazhou Cui' ${ }^{2}$, Jinxiang Han ${ }^{2, *}$ \\ ${ }^{1}$ School of Medicine and Life Sciences, University of Jinan-Shandong Academy of Medical Science, Ji'nan, China; \\ ${ }^{2}$ Key Laboratory for Rare Disease Research of Shandong Province, Key Laboratory for Biotech Drugs of the Ministry of Health, \\ Shandong Medical Biotechnological Center, Shandong Academy of Medical Sciences, Ji'nan, China.
}

\begin{abstract}
Summary Fibrodysplasia ossificans progressive (FOP) is an extremely rare autosomal dominant disorder characterized by congenital malformations of the great toes and progressive heterotopic ossification that can induce a disabling second skeleton. Spontaneously occurring flare-ups can cause inflammatory soft tissue to swell, followed by progressive and disabling heterotopic endochondral ossification. FOP is very rare, with an estimated incidence of one case per two million individuals. There is no definitive treatment for FOP, but the longevity of patients with FOP can be extended by early diagnosis and appropriate prevention of flaresup. Some promising treatment strategies and targets have recently been reported. The current review describes the classical phenotype and genotype of FOP, useful methods of diagnosing the condition, therapeutic approaches and commonly used drugs, and experimental models used to study this disease.
\end{abstract}

Keywords: Fibrodysplasia ossificans progressive, phenotype and genotype, disease modeling, induced pluripotent stem cells

\section{Introduction}

Fibrodysplasia ossificans progressive (FOP), also known as myositis ossificans (1), is a rare autosomal dominant disorder with an incidence of one in two million births with no sexual, racial, or regional predisposition (2). Most patients are scattered around the world except in instances of familial inheritance (3). The earliest reports of FOP by Patin (1692) and Freke (1739) describe its symptoms (4). Later, Stonham, Burton-Fanning, and other physicians reported patients of different genders, ages, and even entire families with FOP and their phenotypes (5).

Abnormal ossification of the joints and soft tissues such as skeletal muscles, tendons, and ligaments (without myocardium and smooth muscle) and congenital hallux valgus are two typical symptoms of FOP (6).

\footnotetext{
*Address correspondence to:

Dr. Jinxiang Han, Key Laboratory for Rare Disease Research of Shandong Province, Key Laboratory for Biotech Drugs of the Ministry of Health, Shandong Medical Biotechnological Center, Shandong Academy of Medical Sciences, Ji'nan, Shandong 250062, China.

E-mail: jxhan9888@aliyun.com
}

Heterotopic ossification (HO) is often associated with disability, such as skeletal deformities (trunk, limb, and facial deformity), chronic pain, growth defects, and stiffness. FOP seriously affects the quality of life and the mental health of patients. The average life expectancy of patients with FOP is no more than 40 years (7). The specific pathogenesis of FOP is not yet clear, and the early phenotype of the disease is easily confused with other diseases, including tumors, fibromas, and bursitis, resulting in its misdiagnosis (8). Moreover, there is no effective treatment for the disease $(9)$.

Here, epidemiological studies on FOP and some common mutations are summarized. Clinically treating the condition is difficult, but diagnosis and treatment of the conditions are making progress. Moreover, experimental models are being used to identify the mechanism of onset of FOP. Greater understanding of the prevalence and symptoms of FOP would facilitate a definitive diagnosis and identify effective precautionary measures. Every step would help to prolong the life-span and improve the quality of life for patients.

\section{Prevalence of FOP}

FOP is an extremely rare, autosomal dominant disease 
with a prevalence of $1 / 2,000,000$ (2). Ninety-five percent of patients manifest $\mathrm{HO}$ before the age of 15 , and the latest report of the oldest patient with $\mathrm{HO}$ involves a patient who was 56 years of age $(10,11)$. According to the CEMARA and PMSI databases, the average age of patients with FOP was 25.5 years, the average age of onset was 7.1 years, and the average age at diagnosis was 10.2 years (11).

Statistics for Europe indicate that 30 cases have been confirmed in the UK among about 49 million residents, with a prevalence of 0.61 per million. Spain is estimated to have an incidence of 0.36 per million (12), and French data indicate a prevalence of 1.36 per million. These figures are roughly similar to the international prevalence of the condition (11).

At present, most patients reported are in the United States, accounting for about $25.6 \%$ of all registered patients. This is followed by China, which accounts for about $10.8 \%$ of registered patients. Patients with FOP in Brazil account for about $8.4 \%$. Compared to European and American patients, Asian patients are younger (3). Despite the extremely low incidence of FOP, there are still a large number of patients with FOP in China due to its huge population. Although definite figures for China are still unclear, the prevalence of FOP can be used to estimate the number of patients. Based on the incidence of FOP, there are at least 650 patients with FOP in China (7). For various reasons such as the level of medical research into the condition, however, only about 70 cases are reported, accounting for no more than $12 \%$ of all such patients in China. Understanding of the symptoms and mutations of FOP needs to be increased and the condition needs to be better diagnosed.

\section{Mutations and diagnosis}

The types of mutations of FOP in China are the same as those in other countries and regions (7). According to that study, $92 \%$ patients have the "classic" clinical presentation of FOP with a mutation of the ACVR1/ $A L K 2$ gene (R260H,c. $617 \mathrm{G}>\mathrm{A})$, while the remaining $8 \%$ have atypical symptoms with mutations at other sites of ACVR1/ALK2 or other bases of $\mathrm{R} 260 \mathrm{H}$.

So far, 13 missense mutations and a 3-base deletion mutation have been found in FOP, and the detailed types and phenotypes of common mutations are shown in Table $1(2,7,10,13,14)$.

The "classic" clinical presentation of FOP with a mutation of the ACVR1/ALK2 gene (R260H, c. $617 \mathrm{G}>\mathrm{A}$ ) induces structural changes in the GS domain. Eighty percent of patients with this mutation may have a congenital big toe (hallux valgus deformity), and some may exhibit soft tissue swelling leading to the formation of abnormal bone in the first decade of life (15). More than $90 \%$ of "classic" patients have a tumor in the tibia and more than $80 \%$ have a vertebral deformity (16). However, $1.5 \%$ of patients with this mutation also have a thumb deformity just like those with G356D (G328 $\mathrm{R} / \mathrm{W} / \mathrm{E}$ ) mutations, and some patients with $\mathrm{R} 260 \mathrm{H}$ will have cataracts, delayed growth, or other atypical symptoms (14).

In the early stages, $80 \%$ of patients with FOP often only have an obvious phenotype-malformations of the great toes - but trauma and infection may lead to abnormal bone formation from soft tissue swelling (8). Trauma, surgery, intramuscular injections, and immune injections cause swelling of soft tissue, and the occurrence of flare-ups is believed to signal the onset of HO (17). Inflammation of soft tissue can gradually infect skeletal muscles, tendons, ligaments, fascia, and aponeuroses, causing abnormal bone formation in these areas, and abnormal bone formation ultimately affects the patient's ability to move as well as the patient's lifespan. Though bone formation is episodic,

Table 1. Common mutations of FOP

\begin{tabular}{|c|c|c|c|}
\hline Codon & Nucleotide & Domain & Features \\
\hline $\mathrm{R} 206 \mathrm{H}$ & $\begin{array}{l}605 \mathrm{G}>\mathrm{T} \\
617 \mathrm{G}>\mathrm{A}\end{array}$ & GS & $\begin{array}{l}\text { i) Characteristic malformations of great toe, ii) HO, iii) Tibialosteochondromas, } i v \text { ) Spine } \\
\text { malformations, } v \text { ) Broad femoral necks }\end{array}$ \\
\hline Q207E & c. $619 \mathrm{C}>\mathrm{G}$ & GS & $\begin{array}{l}\text { i) Characteristic malformations of great toe, ii)HO, iii) Tibialosteochondromas, } i v \text { ) Spine } \\
\text { malformations, } v \text { ) Broad femoral necks }\end{array}$ \\
\hline R202I & $605 \mathrm{G}>\mathrm{T}$ & GS & i) $\mathrm{HO}, i i)$ One short great toe \\
\hline G325A & $974 \mathrm{G}>\mathrm{C}$ & PK & i) Characteristic malformations of great toe, $i i$ ) Late-onset $\mathrm{HO}$ \\
\hline $\begin{array}{l}\text { G328W } \\
\text { G328E } \\
\text { G328R }\end{array}$ & $\begin{array}{l}\text { c. } 982 \mathrm{G}>\mathrm{A} \\
\text { c. } 982 \mathrm{G}>\mathrm{T} \\
\text { c. } 983 \mathrm{G}>\mathrm{A}\end{array}$ & PK & i) HO, ii) Short broad femoral necks, iii) Thumb malformations \\
\hline G356D & $1067 \mathrm{G}>\mathrm{A}$ & PK & i) $\mathrm{HO}$, ii) Spine malformations, iii) Medial tibialosteochondromas \\
\hline $\begin{array}{l}\mathrm{R} 258 \mathrm{~S} \\
\mathrm{R} 258 \mathrm{G}\end{array}$ & $\begin{array}{l}774 \mathrm{G}>\mathrm{C} \\
774 \mathrm{G}>\mathrm{T}\end{array}$ & PK & i) $\mathrm{HO}$, ii) Cognitive impairment, iii) Diffuse scalp hair thinning \\
\hline R375P & c. $1124 \mathrm{G}>\mathrm{C}$ & PK & i) $\mathrm{HO}, i i)$ Normal or minimal changes in great toes \\
\hline
\end{tabular}

FOP, fibrodysplasia ossificans progressiva; GS, glycine-serine-rich domain; $\mathrm{HO}$, heterotopic ossification; PK, protein kinase domain. 
disability is cumulative (17). Loss of mobility or even chewing ability can be caused by severe osteogenesis abnormalities, so most patients have to rely on wheelchairs to move around by the third decade of life (18). Death due to FOP is caused by the complications of thoracic insufficiency syndrome. Deformities of the joints, limbs, and face also place the patient under enormous psychological strain.

Since there is no effective treatment for FOP, diagnosis of the disease needs to be improved and prevention action needs to be taken to delay its progression. Early diagnosis has become the key to extending the life of patients with FOP. However, 90\% of patients with FOP are misdiagnosed in the early stages of the disease. Since there are no diagnostic indicators of FOP, doctors and patients lack understanding of FOP and the early symptoms are not taken seriously, causing a delay in treatment. In specific terms, about $90 \%$ of patients with FOP worldwide have been misdiagnosed, and $67 \%$ of patients have received incorrect or unnecessary treatment. Treatment or diagnostic techniques such as removing excess bone and a biopsy can cause iatrogenic injury that accelerate HO (13). Improper treatment has caused irreparable damage or permanent disability to more than $50 \%$ of patients (17). Differentiating FOP from tumors, fibromas, and bursitis is essential to diagnosis. A typical mutation of R206H, which accounts for the highest proportion of patients overall, causes flare-ups in the first decades of life (16). Therefore, pediatricians and parents must be alert to congenital deformities of the great toes and soft tissue swelling in children consider the likelihood of FOP (19).

Before HO develops, routine physical examinations, including a radiographic skeletal survey, will not provide sufficient evidence to definitively diagnose FOP. The most authoritative indicator is the detection of the $A C V R 1 / A L K 2$ gene. Kaplan et al. obtained genomic DNA from 7 children suspected of having FOP after venipuncture (19). A genetic analysis confirmed that the 7 patients had an $A C V R 1 / A L K 2(\mathrm{R} 206 \mathrm{H}, \mathrm{c} .617 \mathrm{G}>\mathrm{A})$ mutation. Single gene detection allows rapid and accurate diagnosis of patients with FOP before the onset of HO. Without a clear goal or obvious disease phenotype, whole genome sequencing or whole-exome sequencing (WES) is an effective means of reducing the trauma caused by a biopsy, improving the accuracy of diagnosis, avoiding a tedious physical examination, and it also equally helps to identify other rare diseases like FOP $(20,21)$.

After HO develops, progressive extra-skeletal ossifications become typical deformities of FOP. In addition to clinical manifestations, imaging analysis (CT and MRI) is an important method of diagnosis. CT clearly reveals typical HO (8). MRI is also an important tool for diagnosis of FOP because it can reveal preosseous lesions, usually appearing as soft tissue swelling, and skeletal malformations. After HO occurs, plain
$\mathrm{X}$-rays can reveal abnormal osteogenesis. FOP cannot be diagnosed prenatally (22).

Although there is no effective treatment for FOP, prompt diagnosis can allow disease progression to be delayed, because patient can avoid intramuscular injections, tooth modifications which can cause wound $(23,24,25)$. Prevention of trauma and infection is crucial before flare-ups occur (26). Patients should not enter dangerous areas or participate in strenuous activities. Living arrangements need to be improved and protective devices such as helmets need to be worn. Special attention should be paid to avoiding surgical procedures because trauma resulting from surgery can cause massive HO (11).

\section{Existing and potential treatments}

Patients with FOP are generally normal except for congenital great toe deformities in infancy. Fifty percent of flare-ups are caused by trauma, viral infection, intramuscular injections, muscle strain, and excessive fatigue in the first decade, resulting in swelling of the soft tissue and abnormal ossification of the muscles and ligaments $(20,25)$. There is no effective treatment for FOP, but some drugs can be used to relieve initial symptoms.

When flare-ups begin, a brief 4-day course of high-dose corticosteroids such as prednisone can be used to relieve inflammation and tissue edema, but corticosteroids only can be used to relieve inflammation in areas such as the mandibular joint (27). The frequent use of corticosteroids to treat swelling in the trunk and neck is not recommended due to the difficulty in assessing the onset of flare-ups (8).

When corticosteroids are discontinued, mast cell inhibitors, aminobisphosphonates, non-steroidal antiinflammatory drugs, and COX-2 inhibitors could be used to treat later flare-ups. A small dose of a muscle relaxant may help to relieve muscle spasms $(27,28)$. Non-steroidal anti-inflammatory drugs inhibit the synthesis of prostaglandin, which induces resistant $\mathrm{HO}$ in animal models. Clinically, steroids, non-steroids, and anti-inflammatory drugs can mitigate inflammation and pain, but they cannot reduce the frequency of HO. Aminobisphosphonates affect the function and survival of osteoclasts, thus influencing bone formation, but the efficacy and safety of these drugs have not been established (29).

At present, effective drugs are a key area of study. The $A C V R 1 / A L K 2$ mutation causes partial deletion of the $A C V R 1 / A L K 2$ inhibitory protein FKBP12, so $A C V R 1 / A L K 2$ remains weakly activated in the absence of stimulation by BMP signals, causing HO (30). Therefore, one potential strategy would be to inhibit the activity of pathways related to the ACVR $1 / A L K 2$ gene to inhibit abnormal bone formation (31). As an example, LDN-193189, optimized by dorsomorphin, 
is a ALK2 protein inhibitor that repairs and maintains abnormal FOP-iPSc cells in vitro, and there is evidence of the therapeutic value of this drug in treating FOP (32). The other strategy would be to inhibit inflammation or to inhibit of osteoblastic progenitor cell activity (the RAR gamma agonist palovarotene) (33). Hindering the microenvironment for $\mathrm{HO}$ is a possible strategy. As an example, imatinib has a positive effect on multiple FOP related targets, and a clinical trial has demonstrated that it inhibits $A C V R 1 / A L K 2$ signaling, inflammatory triggers, pre-osseous fibro proliferative cells, and stimulatory mast cells. Kaplan et al. proved that imatinib significantly reduced the incidence of flare-ups (9).

New drug targets have been discovered with the increasing understanding of the pathogenesis of FOP. Many drugs, such as imatinib, are in clinical trials, and appropriate drugs may be available in the near future because of better understanding of the mechanism of onset of FOP.

\section{Cells models of FOP}

Studies on FOP are mainly focused on the specific mechanism of onset of $\mathrm{HO}$ and drug screening $(8,12,34)$. The nature of FOP is particularly problematic because of the difficulty in acquiring living tissue to study the mechanisms of the disease. Minor trauma or an infection may cause tissue swelling followed by development of $\mathrm{HO}$ in the ligaments and connective tissue (15). At present, the main models used to study the pathogenesis of FOP are mouse cells, knockout mice, and induced pluripotent stem cells (25).

The cells most often used to model FOP are mouse cells (35). When studying the abnormal expression mechanism of pathogenic ACVR1/ALK2, different researchers have chosen different cell models, and their results differ. Vectors containing mutated ACVR1/ $A L K 2$ have been transfected into cells such as U-2OS (36), MC3T3-E1 (37), and C2C12 (38), but levels of Smad1/5/8 expression differed. In addition to the transfection process (expression and transfection efficiency), the cell type may account for differences in expression $(39,40)$. Patients FOP have endochondral ossification, so many studies have focused on cells related to chondrocytes. The differentiation of mouse embryonic fibroblasts into chondrocytes demonstrates that $A C V R 1 / A L K 2$ is a key factor in chondrogenesis. Embryonic fibroblasts, the origin of mouse mesenchymal cells, can be obtained from the head and limbs of mouse embryos. A rat chondrocyte cell line (ATDC5) expressing BMP-responsive luciferase has been used in high throughput drug screening. The cells can differentiate into mature chondrocytes when cultured in differentiation medium, and drugs that down-regulate the ACVR1/ALK2 gene could be distinguished based on the intensity of the fluorescence signal, providing a basic model for drug screening and retesting of existing drugs (25).

ACVR1/ALK2 gene knockout mice are commonly used (41). Most knockout mice have the FOP phenotype. Murine cells and mice as models of FOP have indeed made great progress, but mice and murine cells cannot meet more detailed experimental needs. There are certain interspecies differences between mice and humans. For example, some knockout mice die during the perinatal period, so more appropriate models are urgently needed (42). Dermal fibroblasts obtained from patients with FOP are more suitable. A 3-mm thick piece of skin is removed from a patient with FOP and then macerated and cultured. Mineralization is then induced to study the role of TGF in osteogenic differentiation. Since trauma can easy trigger flare-ups in patients with FOP, sampling must be performed very carefully and skillfully to avoid trauma or infection (43).

In 2006, Takahashiand Yamanaka induced somatic cell reprogramming with a recombinant factor, thus obtaining induced pluripotent stem cells (iPSc) (44). This new technique has opened up new avenues and methods of studying the biological characteristics of many diseases (45). iPSc have several advantages. First, iPSc have a potent capacity for self-renewal and grow rapidly. In vitro experiments have been able to provide large quantities of needed cells, avoiding the tedious process of obtaining primary cells. Second, their potential for differentiation enables iPSc to differentiate into specific cells, providing cells at different stages of differentiation (46). iPSc can be obtained from somatic cells without causing ethical issues. With individual specificity, iPSc can carry disease-related pathogenic genes and an individual's specific genetic background (47). The induction of iPSc in vitro rapidly and effectively indicates the phenotype of disease in an individual specific background. A variety of somatic cells can be

Table 2. Induced pluripotent stem cell models of FOP

\begin{tabular}{lllll}
\hline Sample & Types & Somatic cell & Vector & Ref. \\
\hline 4 patients & R206H and G356D & Skin fibroblasts & Sendai virus & $(32)$ \\
2 patients & R206H & Urine Cell & Episomal vectors & $(48)$ \\
purchased & R206H & Human dermal fibroblasts & Episomal vectors & $(49)$ \\
2 patients & R206H & Urine & Sendai virus vector & $(50)$ \\
5 patients & R206H & Primary human dermal fibroblasts & Retroviruses and integration-free episomal plasmid & $(51)$ \\
5 patients & R260H & Primary human dermal fibroblasts & Retroviruses and integration-free episomal plasmid & $(40,52,53)$ \\
4 patients & R206H & Fibroblasts & Retrovirus or episomal plasmids & $(54)$ \\
\hline
\end{tabular}

FOP, fibrodysplasia ossificans progressiva. 
reprogrammed into stem cells, including skin fibroblasts (32) and kidney epithelial cells (48), and Sendai virus and non-integration vector can be used as programming tools (49).

iPSc have been obtained by somatically reprogramming cells from patients with FOP. This provides a new, more accurate and appropriate cell model for the study of the pathogenesis of FOP. Hamasaki et al. used incompletely reprogrammed FOP-iPSc as an alternative tool to screen new drugs (32). Hino et al. induced chondrogenic differentiation of MSC cells from FOP-iPSc and concluded that BMP signals were activated by actinA (50). Relevant studies are listed in Table 2.

Surgery is not generally appropriate for patients with FOP, so future studies should focus on drug screening and noninvasive treatment. Intramuscular injections remain a potential risk, so safer dosing schedules should be considered. FOP-iPSc, a strong operational and theoretical basis for elucidation of the pathogenesis of FOP and drug screening, should be the main in vitro model used in future experiments. Effective therapies and drugs to treat FOP should be available in the near future.

\section{Acknowledgement}

This work was supported by the Innovation Project of the Shandong Academy of Medical Sciences.

\section{References}

1. Nilsson OS. Heterotopic ossification. Acta Orthop Scand. 1998; 69:103-106.

2. Miao J, Zhang C, Wu S, Peng Z, Tania M. Genetic abnormalities in fibrodysplasia ossificans progressiva. Genes Genet Syst. 2012; 87:213-219.

3. Pignolo R J, Bedford-Gay C, Liljesthröm M, DurbinJohnson B P, Shore E M, Rocke DM, Kaplan FS. The natural history of flare-ups in fibrodysplasia ossificans progressiva (FOP): A comprehensive global assessmen. J Bone Miner Res. 2016; 31:650-656.

4. Shore EM, Gannon FH, Kaplan FS. Fibrodysplasia ossificans progressiva: Why do some people have two skeletons? Rev Rhum Engl Ed. 1997; 64(Suppl 6):92S-97S.

5. Shore EM, Xu M, Feldman GJ, et al. A recurrent mutation in the BMP type I receptor ACVR1 causes inherited and sporadic fibrodysplasia ossificans progressiva.Nat Genet. 2006; 38:525-527.

6. Hildebrand L, Gaber T, Kühnen P, Morhart R, Unterbörsch H, Schomburg L, Seemann P. Trace element and cytokine concentrations in patients with Fibrodysplasia Ossificans Progressiva (FOP): A case control study. J Trace Elem Med Biol, 2017; 39:186-192.

7. Zhang W, Zhang K, Song L, Pang J, Ma H, Shore EM, Kaplan FS, Wang P. The phenotype and genotype of fibrodysplasia ossificans progressiva in China: A report of 72 cases. Bone. 2013; 57:386-391.

8. Kitterman JA, Kantanie S, Rocke DM, Kaplan
FS. Iatrogenic harm caused by diagnostic errors in fibrodysplasia ossificans progressiva. Pediatrics. 2005; 116:e654-e661.

9. Kaplan FS, Andolina JR, Adamson PC, Teachey DT, Finklestein JZ, Ebb DH, Whitehead B, Jacobs B, Siegel DM, Keen R, Hsiao E, Pignolo RJ. Early clinical observations on the use of imatinib mesylate in FOP: A report of seven cases. Bone. 2017; pii: S87563282(17)30245-4. doi: 10.1016/j.bone.2017.07.019.

10. Whyte MP, Wenkert D, Demertzis JL, DiCarlo EF, Westenberg E, Mumm S. Fibrodysplasia ossificans progressiva: Middle-age onset of heterotopic ossification from a unique missense mutation (c.974G $>$ C, p.G325A) in ACVR1. J Bone Miner Res. 2012; 27:729-737.

11. Baujat G, Choquet R, Bouée S, Jeanbat V, Courouve L, Ruel A, Michot C, Le Quan Sang KH, Lapidus D, Messiaen C, Landais P, Cormier-Daire V. Prevalence of fibrodysplasia ossificans progressiva (FOP) in France: An estimate based on a record linkage of two national databases. Orphanet J Rare Dis. 2017; 12:123.

12. Morales-Piga A, Bachiller-Corral J, Trujillo-Tiebas MJ, Villaverde-Hueso A, Gamir-Gamir ML, Alonso-Ferreira V, Vázquez-Díaz M, Posada de la Paz M, Ayuso-García C. Fibrodysplasia ossificans progressiva in Spain: Epidemiological, clinical, and genetic aspects. Bone. 2012; 51:748-755.

13. Ratbi I, Borcciadi R, Regragui A, Ravazzolo R, Sefiani A. Rarely occurring mutation of ACVR1 gene in Moroccan patient with fibrodysplasia ossificans progressiva. Clin Rheumatol. 2010; 29:119-121.

14. Kaplan F S, Xu M, Seemann P, et al. Classic and atypical fibrodysplasia ossificans progressiva (FOP) phenotypes are caused by mutations in the bone morphogenetic protein (BMP) type I receptor ACVR1. Hum Mutat. 2009; 30:379-390.

15. Pacifici M, Shore E M. Common mutations in ALK2/ ACVR1, a multi-faceted receptor, have roles in distinct pediatric musculoskeletal and neural orphan disorders. Cytokine Growth Factor Rev.2016; 27:93-104.

16. Deirmengian GK, Hebela NM, O'Connell M, Glaser DL, Shore EM, Kaplan FS. Proximal tibial osteochondromas in patients with fibrodysplasia ossificans progressiva. J Bone Joint Surg Am. 2008; 90:366-374.

17. Pignolo R J, Shore E M, Kaplan F S. Fibrodysplasia ossificans progressiva: Clinical and genetic aspects. Orphanet J Rare Dis.2011; 6:80.

18. Kaplan FS, Pignolo RJ, Shore EM. From mysteries to medicines: Drug development for fibrodysplasia ossificans progressive. Expert Opin Orphan Drugs. 2013;1:637-649

19. Kaplan FS, Xu M, Glaser DL, Collins F, Connor M, Kitterman J, Sillence D, Zackai E, Ravitsky V, Zasloff M, Ganguly A, Shore EM. Early diagnosis of fibrodysplasia ossificans progressiva. Pediatrics. 2008; 121:e1295-1300.

20. Liu H, Sawyer SL, Gos M, Grynspan D, Issa K, Ramphal R, Rotaru C; FORGE Canada Consortium, Majewski J, Boycott KM, Graham G, Bromwich M. Atypical fibrodysplasia ossificans progressiva diagnosed by wholeexome sequencing. Am J Med Genet A. 2015; 167:13371341.

21. Rafati M, Mohamadhashem F, Hoseini A, Hoseininasab F, Ghaffari SR. A novel ACVR1 mutation detected by whole exome sequencing in a family with an unusual skeletal dysplasia.Eur J Med Genet. 2016; 59:330-336.

22. Lin FY, Lin $\mathrm{CH}$, Shu G, Chen CK. Fibrodysplasia 
ossificans progressiva: Initial presentation with a preosseous lesion of the scalp and its MRI appearance. Skeletal Radiol. 2016; 45:991-996.

23. Luchetti W, Cohen RB, Hahn GV, Rocke DM, Helpin M, Zasloff M, Kaplan FS. Severe restriction in jaw movement after routine injection of local anesthetic in patients who have fibrodysplasia ossificans progressiva. Oral Surg Oral Med Oral Pathol Oral Radiol Endod. 1996, 81:21-25.

24. Glaser D L, Kaplan F S. Treatment considerations for the management of fibrodysplasia ossificans progressiva. Clin Rev Bone Miner Metab. 2005; 3:243-250.

25. Glaser D L, Rocke D M, Kaplan F S. Catastrophic falls in patients who have fibrodysplasia ossificans progressiva. Clin Orthop Relat Res. 1998; 346:110-116.

26. Cappato S, Tonachini L, Giacopelli F, Tirone M, Galietta LJ, Sormani M, Giovenzana A, Spinelli AE, Canciani B, Brunelli S, Ravazzolo R, Bocciardi R. High-throughput screening for modulators of ACVR1 transcription: discovery of potential therapeutics for fibrodysplasia ossificans progressiva. Dis Model Mech.2016; 9:685-696.

27. FS Kaplan, EM Shore, DL Glaser, S Emerson, JM Connor. The medical management of fibrodysplasia ossificans progressiva: Current treatment considerations .China Forestry Publishing House, China. 2003; 64:359363.

28. Simmons DL, Botting RM, Hla T. Cyclooxygenase isozymes: The biology of prostaglandin synthesis and inhibition. Pharmacol Rev. 2004; 56:387-437.

29. Schuetz P, Mueller B, Christ-Crain M, Dick W, Haas H. Amino-bisphosphonates in heterotopic ossification: First experience in five consecutive cases. Spinal Cord. 2005; 43:604-610.

30. Chaikuad A, Alfano I, Kerr G, Sanvitale CE, Boergermann JH, Triffitt JT, von Delft F, Knapp S, Knaus P, Bullock AN. Structure of the bone morphogenetic protein receptor ALK2 and implications for fibrodysplasia ossificans progressiva. J Biol Chem. 2012; 287:36990-36998.

31. Dey D, Bagarova J, Hatsell S J, et al. Two tissueresident progenitor lineages drive distinct phenotypes of heterotopic ossification. Sci Trans1 Med. 2016; 8:366ra163.

32. Hamasaki M, Hashizume Y, Yamada Y, Katayama T, Hohjoh H, Fusaki N, Nakashima Y, Furuya H, Haga N, Takami Y, Era T. Pathogenic mutation of ALK2 inhibits induced pluripotent stem cell reprogramming and maintenance: Mechanisms of reprogramming and strategy for drug identification. Stem Cells. 2012; 30:2437-2749.

33. Kaplan F S, Pignolo R J, Mukaddam M M A, et al. Hard targets for a second skeleton: Therapeutic horizons for fibrodysplasia ossificans progressiva (FOP). Expert Opin Orphan Drugs. 2017; 5:291-294.

34. Shore E M, Xu M, Feldman G J, et al. A recurrent mutation in the BMP type I receptor ACVR1 causes inherited and sporadic fibrodysplasia ossificans progressiva. Nat Genet. 2006; 38:525-527.

35. Chakkalakal SA, Zhang D, Culbert AL, Convente MR, Caron RJ, Wright AC, Maidment AD, Kaplan FS, Shore EM. An ACVR1 R206H knock-in mouse has fibrodysplasia ossificans progressiva. J Bone Miner Res. 2012; 27:1746-1756.

36. Yano M, Kawao N, Tamura Y, Okada K, Kaji H. A novel factor, Tmem 176b, induced by activin-like kinase 2 signal promotes the differentiation of myoblasts into osteoblasts. Exp Clin Endocrinol Diabetes. 2014; 122:7-14.
37. Ohte S, Shin M, Sasanuma H, et al. A novel mutation of ALK2, L196P, found in the most benign case of fibrodysplasia ossificans progressiva activates BMPspecific intracellular signaling equivalent to a typical mutation, R206H. Biochem Biophys Res Commun. 2011; 407:213-218.

38. van Dinther M, Visser N, de Gorter DJ, Doorn J, Goumans MJ, de Boer J, ten Dijke P. ALK2 R206H mutation linked to fibrodysplasia ossificans progressiva confers constitutive activity to the BMP type I receptor and sensitizes mesenchymal cells to BMP-induced osteoblast differentiation and bone formation. J Bone Miner Res. 2010; 25:1208-1215.

39. Shen Q, Little SC, Xu M, Haupt J, Ast C, Katagiri T, Mundlos S, Seemann P, Kaplan FS, Mullins MC, Shore EM. The fibrodysplasia ossificans progressiva R206H ACVR1 mutation activates BMP-independent chondrogenesis and zebrafish embryo ventralization. J Clin Invest. 2009; 119:3462-3472.

40. Matsumoto Y, Ikeya M, Hino K, Horigome K, Fukuta M1, Watanabe M, Nagata S, Yamamoto T, Otsuka T, Toguchida J. New protocol to optimize ips cells for genome analysis of fibrodysplasia ossificans progressiva. Stem Cells. 2015; 33:1730-1742.

41. Chakkalakal SA, Uchibe K, Convente MR, Zhang D, Economides AN, Kaplan FS, Pacifici M, Iwamoto M, Shore EM. Palovarotene inhibits heterotopic ossification and maintains limb mobility and growth in mice with the human ACVR1 (R206H) fibrodysplasia ossificans progressiva (FOP) mutation. J Bone Miner Res. 2016; 31:1666-1675.

42. Hatsell S J, Idone V, Wolken D M, et al. ACVR1 R206H receptor mutation causes fibrodysplasia ossificans progressiva by imparting responsiveness to activin A. Sci Transl Med. 2015; 7:303ra137.

43. Micha D, Voermans E, Eekhoff ME, van Essen HW, Zandieh-Doulabi B, Netelenbos C, Rustemeyer T, Sistermans EA, Pals G, Bravenboer N. Inhibition of TGF $\beta$ signaling decreases osteogenic differentiation of fibrodysplasia ossificans progressiva fibroblasts in a novel in vitro model of the disease. Bone. 2016; 84:169180.

44. Takahashi K, Yamanaka S. Induction of pluripotent stem cells from mouse embryonic and adult fibroblast cultures by defined factors. Cell. 2006; 126:663-676.

45. Dimos JT1, Rodolfa KT, Niakan KK, Weisenthal LM, Mitsumoto H, Chung W, Croft GF, Saphier G, Leibel R, Goland R, Wichterle H, Henderson CE, Eggan K. Induced pluripotent stem cells generated from patients with ALS can be differentiated into motor neurons. Science. 2008; 321:1218-1221.

46. Barruet E, Hsiao EC. Using human induced pluripotent stem cells to model skeletal diseases. Methods Mol Biol.2016; 1353:101-118.

47. Cyranoski D. Stem-cell pioneer banks on future therapies. Nature. 2012; 488:139.

48. Cai J, Orlova VV, Cai X, Eekhoff EMW, Zhang K, Pei D, Pan G, Mummery CL, Ten Dijke P. Induced pluripotent stem cells to model human fibrodysplasia ossificans progressiva. Stem Cell Reports. 2015; 5:963-970.

49. Kim BY, Jeong S, Lee SY, Lee SM, Gweon EJ, Ahn H, Kim J, Chung SK. Concurrent progress of reprogramming and gene correction to overcome therapeutic limitation of mutant ALK2-iPSC. Exp Mol Med; 2016; 48:e237.

50. Hildebrand L, Rossbach B, Kühnen P, Gossen M, Kurtz 
A, Reinke P1, Seemann P, Stachelscheid H. Generation of integration free induced pluripotent stem cells from fibrodysplasia ossificans progressiva (FOP) patients from urine samples. Stem Cell Res. 2016; 16:54-58.

51. Hino K, Ikeya M, Horigome K, Matsumoto Y, Ebise H, Nishio M, Sekiguchi K, Shibata M, Nagata S, Matsuda $\mathrm{S}$, Toguchida J. Neofunction of ACVR1 in fibrodysplasia ossificans progressiva. Proc Natl Acad Sci U S A. 2015; 112:15438-15443.

52. Matsumoto Y, Hayashi Y, Schlieve CR, Ikeya M, Kim H, Nguyen TD, Sami S, Baba S, Barruet E, Nasu A, Asaka I, Otsuka T, Yamanaka S, Conklin BR, Toguchida J, Hsiao EC. Induced pluripotent stem cells from patients with human fibrodysplasia ossificans progressiva show increased mineralization and cartilage formation. Orphanet
J Rare Dis. 2013, 8:190.

53. Barruet E, Morales BM, Lwin W, White MP, Theodoris CV, Kim H1, Urrutia A, Wong SA, Srivastava D, Hsiao EC. The ACVR1 R206H mutation found in fibrodysplasia ossificans progressiva increases human induced pluripotent stem cell-derived endothelial cell formation and collagen production through BMP-mediated SMAD1/5/8 signaling. Stem Cell Res Ther. 2016; 7:115.

54. Hayashi Y, Hsiao EC, Sami S, et al. BMP-SMAD-ID promotes reprogramming to pluripotency by inhibiting p16/INK4A-dependent senescence. Proc Natl Acad Sci U S A. 2016; 113:13057-13062.

(Received August 17, 2017; Revised November 16, 2017; Accepted November 24, 2017) 